\title{
A INSERÇÃO DO CURSO DE LIBRAS NA FORMAÇÃO BÁSICA DOS PROFISSIONAIS DE SEGURANÇA PÚBLICA
}

\section{ARTIGO ORIGINAL}

SILVA, Geovane Pereira da ${ }^{1}$

SILVA, Geovane Pereira da. A inserção do curso de libras na formação básica dos profissionais de segurança pública. Revista Científica Multidisciplinar Núcleo do Conhecimento. Ano 04, Ed. 08, Vol. 05, pp. 135-144. Agosto de 2019. ISSN: 24480959, Link de acesso: https://www.nucleodoconhecimento.com.br/lei/insercao-docurso

\section{RESUMO}

O escopo do artigo aqui apresentado e trazer à baila a necessidade da implantação nos cursos de formação básica dos Profissionais de Segurança Pública, o conhecimento da Língua Brasileira de Sinais - LIBRAS como forma de inclusão e garantia da dignidade e de direitos fundamentais da pessoa com deficiência auditiva, a inclusão dessas pessoas ao pleno exercício dos direitos fundamentais de segurança e dignidade. A inclusão só será realmente possível de ser alcançada se a pessoa com deficiência auditiva puder se expressar em LIBRAS na solicitação de um direito, no pedido de um atendimento e for compreendida em seu pleito garantindo-se seu direito e sua dignidade através da autonomia, e esta possibilidade só será possível de alcançar na área de segurança pública, com conhecimento de LIBRAS por parte dos profissionais responsáveis por garantir estes direitos. Portanto a inclusão da disciplina de LIBRAS no currículo de formação básica dos profissionais de segurança pública é de suma importância para atender as quase 30 Milhões de Pessoas que tem de surdez no Brasil.

\footnotetext{
${ }^{1}$ Especialista em Segurança Pública e Direitos Humanos, Bacharel em Direito.
} 
Palavras Chaves: Segurança Pública, LIBRAS, direito, surdez.

\section{INTRODUÇÃO}

A Segurança pessoal é um direito fundamental e previsto na Declaração Universal dos Direitos Humanos e na Constituição Federal, tamanha a sua importância, que o cidadão não tem como exercer com tranquilidade seus outros direitos sem sentir-se seguro para sair de casa ou mesmo dentro de sua própria residência.

Parte do Estado a Obrigação de fazer a segurança pública por meio das mais diversificadas formas de polícia, exercendo desta forma o poder cedido pelo povo par uso da força e coerção para manutenção da ordem, paz e tranquilidade pública trazendo aos cidadãos uma sensação de segurança, a confiança de que o estado representado por seus profissionais encarregados da aplicação da lei.

Deste modo a sensação de segurança deve ser universal quando uma pessoa precisa de ajuda e recorre a um profissional de segurança pública este deve de pronto prestar o auxílio ou o socorro necessário a este cidadão, mas o que fazer quando o profissional não consegue se quer compreender o que o solicitante está dizendo? Não há como prestar corretamente ou mesmo em um tempo hábil o serviço ou o auxílio ao cidadão, se não for possível compreender o que ele necessita.

Quando uma pessoa com deficiência auditiva necessita de socorro auxílio ou uma informação de uma autoridade policial, somente sabe expressar o que necessita por meio de sinais e gestos, como cidadão dentro de suas limitações pleiteia seus direitos através da sua forma usual e único meio possível de comunicação como no texto de Ronice muller:

A voz dos Surdos são as mãos e os corpos que pensam, sonham e expressam. A Língua de Sinais envolve movimentos que podem parecer sem sentido para muitos, mas que significam a possibilidade de organizar as ideias, estruturar o pensamento e manifestar o significado da vida para os Surdos. Pensar sobre a surdez requer penetrar no mundo dos Surdos e "ouvir as mãos" que com alguns movimentos nos dizem o que fazer para tornar possível o contato entre os mundos envolvidos. Permita- se "OUVIR ESTAS MÃOS", somente assim, será 
possível mostrar aos Surdos como eles podem "OUVIR O SILÊNCIO DA PALAVRA ESCRITA". ${ }^{1}$

Portanto imaginemos como se sente uma pessoa surdo/muda quando aquele que é responsável por garantir o seu direito não consegue the compreender para prestar o auxílio de que ele tanto precisa? É dever do Estado garantir acesso universal a todos os cidadãos ao direito de segurança pública, e segurança não se faz apenas com policiamento ostensivo, mas também em contato com a comunidade, e no atendimento emergencial de suas demandas, conforme:

"Dados da Organização Mundial da Saúde (OMS), de 2015, apontam que no Brasil existe um total de 28 milhões de pessoas com surdez. Isso representa $14 \%$ da população brasileira." ${ }^{2}$ De tal modo que não é possível considerar eficaz um serviço público de segurança que exclui aproximadamente 30 milhões de Brasileiros.

\section{OS SURDOS E A DIFICULDADE DE ACESSO A DIREITOS IMPOSTO PELA BARREIRA DA COMUNICAÇÃO}

A primeira limitação imposta pela falha ou dificuldade na comunicação remonta a tempos imemoriáveis, quando os homens buscavam suas primeiras grandes realizações a mais de 4000 anos atrás relatado na Bíblia Sagrada no livro de Gênesis $11: 7:$

Ele sabia que se continuassem muito unidos, iriam conseguir o que queriam. Por isso Deus confundiu suas línguas e eles não conseguiram se entender mais ${ }^{3}$

Segundo a história bíblica por ocasião da construção da torre de Babel, todos falavam uma mesma língua, sabendo Deus que se todos falassem uma só língua e continuassem unidos conseguiriam o que quisessem até mesmo construir uma torre e chegar aos céus, nota-se que até mesmo do ponto de vista religioso e relatado por divindade que a barreira da comunicação impede o homem de alcançar seus objetivos. Que unidos e se entendendo perfeitamente o homem é capaz de conseguir o que quiser. 
O surdo então sofre limitação muitas vezes por essa barreira chamada comunicação, por causa da sua singularidade linguística que deveria já ter sido implementada no serviço público principalmente em serviços essenciais como a segurança pública, o conhecimento de policiais, bombeiros militares e demais profissionais da Língua Brasileira de Sinais - LÍBRAS é fator fundamental para inclusão da pessoa surda aos atos de exercício pleno de seus direitos.

O uso da língua de sinais é o caminho, mas viável para mudança no atendimento e acesso de pessoas com deficiência auditiva aos serviços públicos necessários para a plenitude do exercício de seus direitos, verificou-se um grande avanço ocorrido no ano de 2002 com a publicação da lei n 10436 que estabelece a Língua Brasileira de Sinais como língua oficial.

Art. 1 É reconhecida como meio legal de comunicação e expressão a Língua Brasileira de Sinais - Libras e outros recursos de expressão a ela associados.

De forma Clara e Precisa o legislador descreve o que é a Língua Brasileira de sinais:

Parágrafo único. Entende-se como Língua Brasileira de Sinais - Libras a forma de comunicação e expressão, em que o sistema Linguístico de natureza visual-motora, com estrutura gramatical própria, constitui um sistema Linguístico de transmissão de ideias e fatos, oriundos de comunidades de pessoas surdas do Brasil. ${ }^{4}$

Com a publicação da lei que reconhece o sistema de Língua Brasileira de sinais LIBRAS como meio legal de comunicação que deve ser utilizada como forma de integração da pessoa com deficiência auditiva, ao meio social e ao acesso a serviços públicos, alimentou-se na comunidade surda uma esperança de dias melhores e mais inclusivos, facilitando acesso dos surdos a alguns direitos e serviços que antes eram embarreirados pela falta ou dificuldade na comunicação.

\section{A SEGURANÇA PÚBLICA NA CONSTITUIÇÃO FEDERAL DE 1988}

A Constituição federal de 1988 é considerada um grande avanço, na garantia dos direitos fundamentais dos cidadãos, tanto que trata primeiramente de tais direitos 
antes mesmo da organização do estado, o direito a segurança é visto na constituição federal desde o preâmbulo:

Nós, representantes do povo brasileiro, reunidos em Assembleia Nacional Constituinte para instituir um Estado Democrático, destinado a assegurar o exercício dos direitos sociais e individuais, a liberdade, a segurança, o bem-estar, o desenvolvimento, a igualdade e a justiça como valores supremos de uma sociedade fraterna, pluralista e sem preconceitos, fundada na harmonia social e comprometida, na ordem interna e internacional, com a solução pacífica das controvérsias, promulgamos, sob a proteção de Deus, a seguinte CONSTITUIÇÃO DA REPÚBLICA FEDERATIVA DO BRASIL ${ }^{5}$. (grifo nosso)

Sendo então vista a segurança como necessidade basilar para o bem estar do cidadão, seguida do direito a igualdade, sendo a igualdade um valor considerado supremo para implantação de uma sociedade fraterna e sem preconceito.

Contudo esse objetivo de uma sociedade igualitária e justa na área da segurança pública só será realmente alcançado, se essa parcela significativa da sociedade que é a comunidade surda, que hoje alcança um número aproximado de 30 milhões de vidas segundo a Organização Mundial da saúde - OMS obtiver acesso pleno aos órgãos encarregados de garantir a segurança pública, através da formação dos profissionais da área de segurança para que tenham compreensão dos pleitos expressados pelos surdos por meio da sua forma singular de comunicação a Língua de Sinais.

A Constituição trata em seu Art. 144 da segurança descrevendo quais são os órgãos responsáveis pela sua execução nas mais diversas formas de policiamento assim temos que:

Art. 144. A segurança pública, dever do Estado, direito e responsabilidade de todos, é exercida para a preservação da ordem pública e da incolumidade das pessoas e do patrimônio, através dos seguintes órgãos:

I - Polícia federal;

II - Polícia rodoviária federal; 
III - Polícia ferroviária federal;

IV - Polícias civis;

V - Polícias militares e corpos de bombeiros militares.

Portanto tais órgãos exercem fator fundamental na vida do cidadão à medida que é necessário reconhecer a segurança pública como garantidora do exercício dos direitos e garantias fundamentais, não se opondo a liberdade sendo dantes garantidora desta, são desta forma as instituições acima elencadas instituições fundamentais do governo para garantia dos direitos do cidadão.

De forma que os Policiais sejam eles civis ou militares devem estar preparados para atender um cidadão que necessite de auxílio, socorro ou para garantir seu acesso de forma plena a algum direito concernente à segurança pública, como garantir então acesso ao direito se o Policial não compreender o cidadão? Sendo impossível a compreensão será inviável o auxílio do estado ora representado pelos profissionais responsáveis pela aplicação da lei.

Contudo ainda que seja de fundamental importância à compreensão da Língua Brasileira de Sinais - LIBRAS por parte dos profissionais de segurança pública para garantir acesso da comunidade portadora de deficiência auditiva ao exercício pleno do direito social de segurança, não existe na grade curricular de formação básica a matéria de Libras que é de vital importância para o bom desempenho destes profissionais que são antes de tudo garantidores de direitos.

Por tudo que foi exposto verifica-se que é de extrema importância a implementação nos cursos de Formação Básica Policiais, ou nos cursos destinados a promoção ou aperfeiçoamento dos referidos profissionais a matéria de libras, para que se faça cumprir de forma plena o direito social de segurança a aproximadamente 30 milhões de Brasileiros e sua inclusão.

Meta inclusiva que já tem previsão o Decreto n 5626 de 22 de dezembro de 2005, que regulamenta a lei $n^{\circ} 10.436 / 2002$, que traz a necessidade da implementação do 
conhecimento de libras pelo poder público bem como pelas empresas concessionárias do serviço público:

Art. 26. A partir de um ano da publicação deste Decreto, o Poder Público, as empresas concessionárias de serviços públicos e os órgãos da administração pública federal, direta e indireta devem garantir às pessoas surdas o tratamento diferenciado, por meio do uso e difusão de Libras e da tradução e interpretação de Libras - Língua Portuguesa, realizados por servidores e empregados capacitados para essa função,(..)

Sem esquecer-se dos Estados o Legislador busca garantir à efetividade da inclusão social da pessoa surda e seu direito a dignidade através de um atendimento em sua linguagem.

§ 2ํㅡ O Poder Público, os órgãos da administração pública estadual, municipal e do Distrito Federal, e as empresas privadas que detêm concessão ou permissão de serviços públicos buscarão implementar as medidas referidas neste artigo como meio de assegurar às pessoas surdas ou com deficiência auditiva o tratamento diferenciado, previsto no caput. $^{6}$ (grifo nosso)

Espera-se que os próximos cursos de formação de profissionais de segurança pública já tenham em sua grade curricular a disciplina de LÍBRAS como forma de Promoção de Direitos Humanos, por meio do tratamento igualitário as pessoas surdas e garantia de acesso aos direitos previstos no real Estado Democrático de Direito.

\section{CONSIDERAÇÕES FINAIS}

É de se reconhecer com os questionamentos levantados que a ausência do curso de LIBRAS na grade curricular dos cursos de formação básica dos Profissionais de Segurança Pública enseja na exclusão de um atendimento mais digno a milhares de pessoas com deficiência auditiva. Problema esse de fácil resolução por parte do Poder público simplesmente com a inclusão da matéria de LIBRAS na formação dos profissionais encarregados da segurança. 


\section{REFERÊNCIAS}

1. MÃOS QUE FALAM. Disponível em: http://www.cvdee.org.br/evangelize/pdf/6_0205.pdf>. Acesso em: 19.03.2019

2. JORNAL DA USP. Quase 30 Milhões De Brasileiros Sofrem De Surdez. Disponível em: https://jornal.usp.br/atualidades/quase-30-milhoes-debrasileiros-sofrem-de-surdez/ Acesso em : 25.03.2019

3. BíBLIA SAGRADA. Livro de Gênesis, capítulo 1, versículo 7.

4. BRASIL. Lei $N^{\circ} 10.436$ De 24 De Abril De 2002. Disponível em: http://www.planalto.gov.br/ccivil_03/leis/2002/10436.htm. Acesso em : 06.04.2019

5. BRASIL. Constituição Da República Federativa Do Brasil De 1988. Disponível em:

http://www.planalto.gov.br/ccivil_03/constituicao/constituicaocompilado.htm. Acesso em: 02.03.2019

6. BRASIL. Decreto № 5.626, De 22 De Dezembro De 2005. Disponível em: http://www2.camara.leg.br/legin/fed/decret/2005/decreto-5626-22-dezembro2005-539842-publicacaooriginal-39399-pe.html. Acesso em 19.03.2019

Enviado: Fevereiro, 2019.

Aprovado: Agosto, 2019. 